\title{
Arterial Stiffness: The New Frontier in Hypertension and Cardiovascular Disease
}

\author{
Erika Maria Gonçalves Campana ${ }^{1,2}$ \\ Universidade de Nova Iguaçu, Nova Iguaçu, $R J$ - Brazil \\ Universidade do Estado do Rio de Janeiro, ${ }^{2}$ Rio de Janeiro, RJ - Brazil
}

Vascular age is a reflection of cardiovascular and non-cardiovascular factors that contribute to accelerated vascular aging (AVA) and stiffness of large elastic arteries, leading to increased cardiovascular morbidity and mortality. ${ }^{1}$ Arterial stiffness has been regarded as an important biomarker in the assessment of subclinical atherosclerosis and cardiovascular risk..$^{1-4}$ The addition of pulse wave velocity (PWV) measurements to traditional risk factors has improved the prediction of the ten-year risk of cardiovascular diseases in $13 \%$ of individuals at intermediate risk. ${ }^{5}$

In addition, the altered behavior of central hemodynamic parameters, such as central systolic blood pressure (cSBP) and the (heart rate-corrected) augmentation index (AI), is influenced by arterial stiffness and plays a crucial role in the interface between the traditional cardiovascular continuum vascular aging continuum, which represents the current view of the pathophysiology of cardiovascular diseases. $^{6-8}$ (Figure 1)

Part of the residual cardiovascular risk in hypertensive patients, a concept that has gained much attention in recent years, has been related to the AVA process. An early detection of this condition allows a more effective cardiovascular protection. In the pathophysiology of the residual risk and development of cardiovascular disease, there is a bidirectional interaction of AVA and hypertension. The accumulation of risk factors contributes to changes in the vessel wall that lead to vascular aging and stiffening of elastic arteries, and consequent elevation of blood pressure levels. In the opposite direction, increased

\section{Keywords}

Vascular Stiffness; Hypertension; Blood Pressure; Indicators of Morbidity and Mortality; Target Organs, Risk Factors. blood pressure promotes arterial stiffening, providing a feedback to the AVA process. ${ }^{2-4}$

The CAFE study ${ }^{9}$ has presented the first evidence of the clinical impact of central hemodynamic parameters and arterial stiffness on the reduction of cardiovascular events. The therapeutic strategy of amlodipine plus perindopril promoted greater reductions in cSBP and cardiovascular events compared with atenolol plus thiazide (control intervention).

Vlachopoulos et al., ${ }^{10}$ produced one of the most striking evidences of the clinical application of arterial stiffness in predicting the risk for cardiovascular events. In a metaanalysis, the authors showed that an increase in aortic PWV by $1 \mathrm{~m} / \mathrm{s}$ was associated with an increase of $15 \%$ in cardiovascular mortality and 15\% in all-cause mortality.

Thus, the main guidelines on cardiovascular disease prevention have incorporated the assessment of arterial stiffness and central hemodynamics for risk stratification, aiming at early recognition of subclinical target organ lesions in patients' follow-up. ${ }^{2-4}$

In the article published in this issue, Barroso et al., ${ }^{11}$ present the results of the comparison of two methods of central pressure and arterial stiffness evaluation applanation tonometry, considered the gold standard, and the oscillometric method that has been recently validated for clinical use. Twenty-seven patients were assessed using both methods. There was no difference in mean cSBP between the methods, but PWV and pulse pressure were underestimated by the oscillometric method. These results validate the oscillometric method for clinical application in the Brazilian population and suggest that patients with elevated PWV detected by the oscillometric method are at elevated cardiovascular risk, expressed by a more aggressive AVA process.

The incorporation of arterial stiffness measures to traditional risk scores and its recognition as a biomarker

Mailing Address: Erika Maria Gonçalves Campana

Av. Abílio Augusto Távora, 2134. Postal Code: 26275-580, Dom Rodrigo, Nova Iguaçu - Brazil.

E-mail: campanaemg@predialnet.com.br, campanaemg@gmail.com 


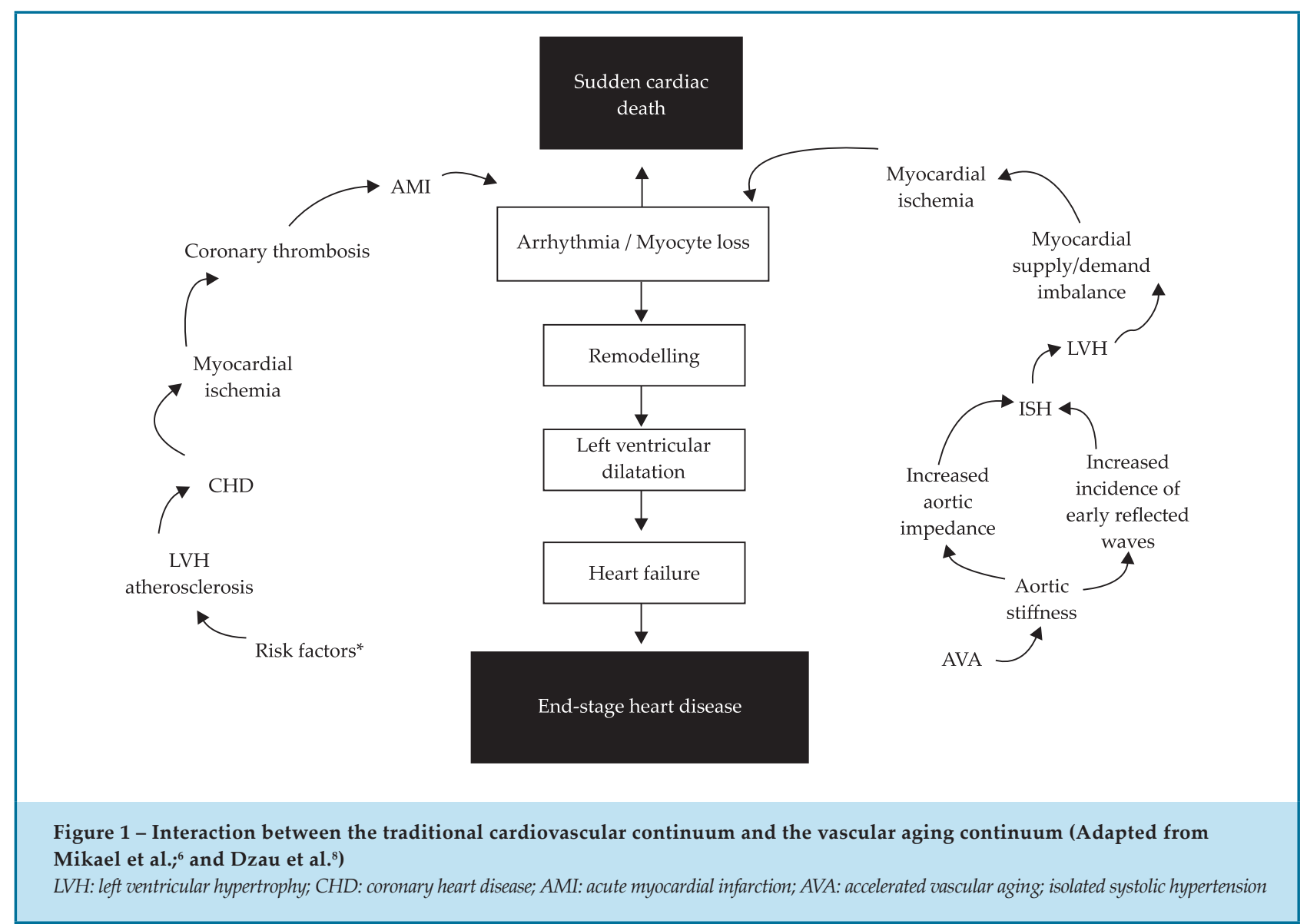

of subclinical target organ lesion, significantly improves the capacity to predict cardiovascular events. This concept adds to the knowledge about the AVA in guiding the diagnosis, risk stratification and treatment of hypertensive patients, allowing a personalization of therapeutic strategies and reduction of hypertension-related risk.

\section{References}

1. Nilsson PM, Boutouyrie P, Laurent S. Vascular aging: A tale of Eva and Adam in cardiovascular risk assessment and prevention. Hypertension. 2009;54(1):3-10

2. Sociedade Brasileira de Cardiologia. VII Diretriz Brasileira de Hipertensão. Arq Bras Cardiol. 2016; 107(3Supl.3):1-83.

3. Whelton PK, Carey RM, Aronow WS, Casey DE Jr, Collins KJ, Dennison Himmelfarb Cetal. 2017 ACC/AHA/AAPA/ABC/ACPM/AGS/APhA/ASH/ ASPC/NMA/PCNA Guideline for the Prevention, Detection, Evaluation, and Management of High Blood Pressure in Adults: Executive Summary: A Report of the American College of Cardiology/American Heart Association Task Force on Clinical Practice Guidelines. Hypertension. 2018;71(6):1269-324.

4. Williams B, Mancia G, Spiering W, Rosei EA, Azizi M, Burnier M, et al. 2018 ESH/ESC Guidelines for the management of arterial hypertension. Eur Heart J. 2018;39(33):3021-104.

5. Ben-Shlomo Y, Spears M, Boustred C, May M, Anderson SG, Benjamin EJ, et al. Aortic pulse wave velocity improves cardiovascular event prediction: an individual participant meta-analysis of prospective observational data from 17,635 subjects. J Am Coll Cardiol. 2014;63(7):636-46.

6. Mikael LR, Paiva AMG, Gomes MM, Sousa ALL, Jardim PC, Vitorino PVO, et al. Vascular Aging and Arterial Stiffness. Arq Bras Cardiol. 2017;109(3):253-8.

7. Roman MJ, Devereux RB, Kizer JR, Lee E, Galloway JM, Ali T, et al. Central pressure more strongly relates to vascular disease and outcome than does brachial pressure: the Strong Heart study. Hypertension. 2007; 50(1):197-203.

8. Dzau VJ, Antman EM, Black HR, Hayes DL, Manson JE, Plutzky J, et al. The cardiovascular disease continuum validated: clinical evidence of improved patient outcomes: part I: Pathophysiology and clinical trial evidence (risk factors through stable coronary artery disease). Circulation. 2006;114(25):2850-70.

9. Williams B, Lacy PS, Thom SM, Cruickshank K, Stanton A, Collier D, et al . for the CAFE Steering Committee and Writing Committee. Differential impact of blood pressure-lowering drugs on central aortic pressure and clinical outcomes: principal results of the Conduit Artery Function Evaluation (CAFE) study. Circulation. 2006;113(9):1213-25.

10. Vlachopoulos C, Aznaouridis K, Stefanadis C. Prediction of cardiovascular events and all-cause mortality with arterial stiffness: a systematic review and meta-analysis. J Am Coll Cardiol. 2010; 55(13):1318-27.

11. Barroso WKS, Gonçalves CF, Berigó JAC, Melo MA, Arantes AC, Lelis ES, et al. Tonometric and Oscillometric Methods for Measurement of Central Blood Pressure Parameters: a Comparison in Patients with Borderline Hypertension or Stage 1 Hypertension. International J Cardiovasc Sc. 2020; 33(2):145-150. 